\title{
"HONOUR"-BASED VIOLENCE AND THE POLITICS OF CULTURE IN CANADA: ADVANCING A CULTURAL ANALYSIS OF MULTISCALAR VIOLENCE
}

\author{
Salina Abji and Anna C. Korteweg
}

\begin{abstract}
Since 2015, in Canada, political discourse on "honour"-based violence has shifted away from highly problematic understandings of "culture" as the cause of violence among racialized, Muslim, and immigrant communities. Instead, talk of culture has dropped out of the equation altogether in favour of more structural definitions of gender-based violence (GBV). In this article, we ask what gets lost when culture is not taken into account when talking about or trying to understand forms of GBV. Drawing from theoretical conceptualizations of culture - defined as "situated practices of meaning-making" that shape all experiences of violence, and societal responses to violence — we argue for a multiscalar approach to culture. To illustrate this framework, we first offer a critical analysis of Aruna Papp's 2012 memoir Unworthy Creature as an exemplar of stigmatizing uses of culture and a key text promoted by the Conservative federal government at the time. We then turn to interviews we conducted with service providers serving South Asian survivors of GBV in Toronto from 2011 to 2013. Our analysis illustrates how to talk about culture as a key ingredient shaping multiscalar violence, regardless of whether that violence occurs in majority or minority communities. We conclude with three policy implications for addressing HBV moving forward.
\end{abstract}

Keywords: culture, gender-based violence, honour-based violence, South Asians, Canada

Salina Abji PhD (corresponding author) is a sociologist and Research Consultant in Toronto, Ontario. Email: salina@,salinaabji.ca

Anna C. Korteweg PhD is Professor of Sociology at the University of Toronto Mississauga, 3359 Mississauga Road, Mississauga, ON L5L 1C6. Email: anna.korteweg@utoronto.ca 
International Journal of Child, Youth and Family Studies (2021) 12(1): 73-92

This research investigates how definitions of culture impact efforts to address so-called honour-based violence (HBV) as a form of gender-based violence (GBV). The Conservative federal government that held power in Canada from 2006 until 2015 approached HBV as a "barbaric cultural practice", a term also applied to forced marriage, polygamy, and female genital mutilation (Zero Tolerance for Barbaric Cultural Practices Act 2015). In our previous work, we have shown how such politicized framings of HBV constitute "culture talk" — that is, politicized uses of culture that frame minority communities as backward or as security threats to Western nations (Abji et al., 2019; Korteweg et al. 2013; see also Mamdani, 2007; Razack, 1994). Importantly, culture talk works to undermine rather than increase access to safety and supports for GBV survivors from minority communities (Abji et al., 2019; Korteweg et al., 2013; see also Jiwani, 2005; Razack, 2003).

More recently, however, public discourse on HBV has shifted. Since the Liberal party came into power in 2015, the federal government has moved away from talk of culture by, for example, removing the phrase "barbaric cultural practices" from legislation and qualifying references to HBV with the phrase "so-called" — as in "so-called honour violence" — a strategy originally developed by advocates to signal the contested nature of the term (Korteweg et al., 2013). In this article, we ask what gets lost when "culture" is rhetorically dropped from discourse directed towards addressing HBV. Overall, what we offer is a critique both of stigmatizing culture talk and of more recent attempts to use culture-neutral definitions of HBV. Specifically, we argue that the culture-neutral approaches to HBV adopted by the government are a shift in the right direction, in that they address the stigmatizing effects of culture talk to some degree. However, such attempts to "de-culture" violence also obscure how all types of violence (and by extension all responses to violence) are situated in culture. Indeed, we suggest that a culture-neutral approach, much like culture talk, closes off possibilities for a comprehensive response to all forms of violence, including GBV.

Drawing from rich theoretical traditions in the conceptualization of culture (e.g., Bourdieu, 1997; Geertz, 1973; Hall, 1997; Swidler, 1986; Williams, 1977), we argue for a more nuanced and systemic approach to culture in contemporary approaches to so-called HBV and GBV. In doing so, we draw on a framework that we have developed over the past 10 years, which posits that culture — which we define as "situated practices of meaning-making" — is a key ingredient for understanding and addressing all forms of violence, including HBV (see Abji et al., 2019; Kortweg et al., 2013; see also Siddiqui, 2000). For example, paying attention to culture as situated practices of meaning-making can provide important insights into how the attitudes of antiviolence workers themselves are imbued with cultural understandings of both GBV and freedom from GBV (Abji et al., 2019). Instead of culture talk or culture-neutral approaches we suggest a third, more nuanced, way of addressing culture that we term "culture as meaning-making". 
International Journal of Child, Youth and Family Studies (2021) 12(1): 73-92

To illustrate how this view of culture as meaning-making can be mobilized in efforts to address HBV, we ground our discussion in research we conducted in Toronto, Canada at the height of public debates on HBV (2011-2013). Our analysis is divided into three parts. The first illustrates the problematic uses of culture talk during this period, with a focus on Aruna Papp's memoir Unworthy Creature: A Punjabi Daughter's Memoir of Honour, Shame and Love (Papp \& Kay, 2012). This book was endorsed by then Minister of the Status of Women, Conservative Member of Parliament Rona Ambrose, as evidence of the "terrors of the 'culture of honour'". Papp subsequently claimed to have influenced the Conservative federal government's framing of HBV as a "barbaric cultural practice" in their 2015 Zero Tolerance for Barbaric Cultural Practices Act (see Abji et al., 2019). We then turn to interviews that we conducted in this time period with 15 service providers who had extensive experience working with diverse South Asian communities in the Greater Toronto Area (GTA). Through our analysis of service providers' nuanced accounts of the forms of GBV that South Asian families were experiencing (including so-called HBV), we highlight the practices of meaning-making — which we would describe as cultural — that underpinned their conceptions of violence. Further, we show how the forms of GBV that service providers described were multiscalar, and in so doing, we develop a conceptualization of violence as structured by multiple and intersecting forces of family, society, economy, and the state.

In the second part of our analysis, we show how our interviewees rejected stigmatizing uses of culture (culture talk) to describe GBV. We also highlight how problematic uses of culture talk obscured the multiscalarity of violence. In the third part, we discuss the importance of culture as meaning-making for developing policy approaches that take into account the complexities of GBV in a wide range of expressions. To illustrate this point, we conclude the article with three concrete policy implications that this approach to culture suggests for addressing HBV.

Through this analysis, we offer not only an alternative way to talk about culture, but also one that takes seriously the contexts in which the practice of GBV and HBV are embedded. If we think about cultures as situated processes of meaning-making that have contexts and occur within broader, multiscalar, social structures, this increases the likelihood that responses to violence will succeed. We argue that when we bring culture as meaning-making together with a multiscalar analysis, we are better positioned to address GBV as an issue that affects not only survivors, but their families and communities as well. In what follows, we start by outlining the current literature on HBV and the politics of culture, then turn to our methodology and analysis.

\section{Understanding “Honour"-Based Violence and the Politics of Culture}

"Honour"-based violence is typically defined in the literature as a family-initiated, planned response to the perception that a daughter or other female family member has violated the family's honour in the eyes of the community (Sev'er \& Yurdakul, 2001). Although on the surface this definition may seem to offer an objective way to capture a particular form of violence, in the contemporary immigration context such apparently objective definitions of violence are in fact politicized. Such definitions also fail to integrate a view of violence as multiscalar, where we 
define multiscalarity as the complex intersection of spaces (local, national, transnational) with the multivalent expressions of power (discourse, legality, materiality) that shape life (Guimont Marceau et al., 2020; Laine, 2016). In contemporary accounts that attempt to link HBV to a people's culture, the multiscalar context and forms of violence that occur are ignored through a process of "racialization", by which we mean the process of coming to view a group of people as racially marked, with the perceived practices of some members of the group becoming reified ("biologized", or treated as innate) to mark the entire group as less civilized or less capable of thoughtful action than the groups that form "majority society" (Omi \& Winant, 2014). Rather than being understood as one of the myriad forms that familial and domestic violence can take, HBV becomes a sign of immigrant backwardness (Abu-Lughod, 2011; Korteweg, 2014; Razack, 2008). In addition, HBV is often erroneously seen as particularly a "Muslim problem" (Abu-Lughod, 2011; Zine, 2009).

With regard to South Asian communities in the Canadian context, particularly those in the Greater Toronto area ${ }^{1}$, we pointed out in earlier work with Lisa Barnoff and Deepa Mattoo (Korteweg et al., 2013) that violence against women:

... has often been publicly understood through highly problematic ideas about culture. Media representations of the murders of Aqsa Parvez in 2007, and the Shafia sisters and their aunt in 2009 , furthered the racialization and stigmatization of these women's communities rather than digging deeper into the complexities of the extreme violence they experienced (Korteweg, 2012). Such popular discussions position "culture" as producing a "backward" civilization in which women have little value other than as the containers of their family's "honour" (Korteweg and Yurdakul, 2009, 2010; Razack, 2004, 2007, 2008). These uses of culture impede women's ability to access social, civil, and human rights: research shows that when inequality combines with cultural stigmatization, immigrant women and girls experiencing violence may fail to seek help, risk having their needs misunderstood, face overt and covert discrimination from service providers, or fear being ostracized by their own communities when they try to access services (Korteweg and Yurdakul 2010; Berman et al 2009; Moffat et al 2009; Dustin and Phillips 2008; Shirwadkar 2004; Raj and Silverman 2002; Jiwani 2005). (p. 1)

In other words, while we do not deny the existence of extreme forms of violence justified by perpetrators in the name of "honour", we also argue that to be properly considered such violence must be carefully situated within existing structural contexts.

\footnotetext{
${ }^{1}$ South Asian communities in the Greater Toronto Area (GTA) are relatively well established and continue to grow. According to the 2016 census, South Asians constitute the largest group of visible minorities in Toronto, about 13\% of the total population. These communities are highly diverse.
} 
Based on the literature and our own prior work in this area, our analytical approach views culture as a key ingredient for understanding and addressing all forms of violence, including GBV. As detailed in Abji et al. (2019), we use culture as an analytical category, one that brings into view socially embedded processes of meaning-making in which every act of violence and every response to violence has a multiscalar context. Too often the interpretive potential of understanding culture as an analytical category is superseded by the imposition of an uncritical, "commonsense" use of culture as the factor that determines the behaviour of a given community (Fischer \& Dahinden, 2017). We label as "culture talk" such uses of culture to explain violence, in which culture is treated as ossified, ahistorical, and unchanging (see also Mamdani, 2007; Razack, 2008). The ubiquity of culture talk, with its gendered racializing effects, hinders the efforts of activists and advocates whose hopes of addressing GBV hinge on promoting an understanding of the effect of culture as socially-embedded processes of meaning-making. Even raising the issue of culture at all risks activating culture talk.

We use the phrase "culture as meaning-making" in order to get at the ways in which culture is dynamic and continually shifting, rather than being a static, deterministic, or unitary force. We draw on work by Raymond Williams (1977), Stuart Hall (1997), and Clifford Geertz (1973), who, in different ways, theorize culture as a continual and complex set of processes through which we come to understand our own subjectivity, our sense of relationship with others, and the relationship between individuals, institutions, and social, political, and economic forces. This understanding of culture as meaning-making is also rooted in various readings in sociology and anthropology, including Swidler (1986) and Bourdieu (1977), who in their own ways centre processes of meaning-making to understand the structuring force of culture. We are also influenced by Volpp (2000), who held that racialized persons are objectified in law "as culture", while white persons are subjects who "have" culture.

As such, culture as meaning-making informs all practices of violence whether perpetrated by majority or minority members of society. Moreover, these processes of meaning-making also condition all responses to violence at the individual and institutional levels. By directing analytical attention towards processes of meaning-making we gain additional insight into the multiscalar forces associated with state power, the political economy, and migration regimes that shape expressions of and responses to GBV in all its forms.

\section{Methodology}

In our analysis, we draw on the framework we developed and described in earlier publications (see Abji et al., 2019; Korteweg, 2014; Korteweg et al., 2013; Korteweg \& Yurdakul, 2009, 2010). The framework is based in part on research we conducted between 2011 and 2013 during a period of heightened attention to HBV in Canada. We conducted qualitative interviews with 15 professionals in the service sector who had long-standing engagements with addressing GBV 
among the various South Asian communities of the GTA. The research project received approval from the University of Toronto's Ethics Review Board.

All but two of the interviews were conducted one-on-one by the first author, who is herself South Asian and an activist on these issues. These interviews had an assumption of familiarity and a feeling of ongoing conversation despite this being a first meeting. This changed somewhat for the two interviews where both authors were present, the second author being of white immigrant background. In those cases, interviewees placed more emphasis on explanation to a presumed outsider.

While our sample was by no means comprehensive, we tapped into a cluster of people recognized within this community of service providers as key actors in the field. Many of them were highly educated with advanced degrees in social work and other fields. Almost all had worked in the social service sector for over a decade; some had three decades or more of experience. Fourteen of our interviewees identified as women, one as a man. All self-identified as members of the GTA's various South Asian communities.

The participants in our sample reflected the diversity of South Asian communities in the GTA more broadly. South Asian communities in Canada are culturally and linguistically diverse (South Asian Legal Clinic of Ontario [SALCO], 2013). They represent a range of settlement patterns (from newcomers to great-grandchildren of immigrants) and religious communities (including Muslim, Sikh, Hindu, and Christian, among others), and vary widely in socioeconomic status. The lives of immigrants, like those of all Canadians, are shaped in the intersections of the political, economic, and social forces that structure their experience. We identified interviewees who worked within different communities to gain a richer account of the issues surrounding HBV and GBV.

The interviews, which lasted between 1 and 3 hours, were recorded and transcribed. All the interviewees were given pseudonyms. We then conducted two rounds of coding, using the qualitative analysis software NVivo. The first round was largely inductive and alerted us to the tensions around the concepts of culture in the interviewees' accounts. We then conducted a focused coding to create a more fine-grained analysis of the specific ways in which the interviewees referenced culture. In general, we followed the methodology of the extended case method (Burawoy, 1998) and critical discourse analysis (van Dijk, 1993; Wodak \& Meyer, 2015) in an attempt to uncover the workings of power through the use of discourse.

In addition to the interviews, we conducted an analysis of parliamentary discussion on the Zero Tolerance for Barbaric Cultural Practices Act 2015. The parliamentary sources were analyzed using the same strategies as the interviews, using NVivo to conduct inductive and focused coding. ${ }^{2}$ We also analyzed the memoir of Aruna Papp (Papp \& Kay, 2012), a social worker whose book

\footnotetext{
${ }^{2}$ This analysis is not directly presented in this article but is part of the larger research project that informs our
} framework for analysis (Abji et al., 2019). 
International Journal of Child, Youth and Family Studies (2021) 12(1): 73-92

and activism informed the passage of the Act. The first author conducted an in-depth analysis of Papp's memoir by hand, focusing on Papp's activation of culture talk to explain violence.

In what follows, we start with Aruna Papp's memoir (Papp \& Kay, 2012) as an example of culture talk that accompanied the intense public scrutiny of HBV that took place under the rightwing Conservative government in Canada (2006-2015). We then show how stigmatizing conceptions of culture and an assumption of immigrant backwardness impacted the people we interviewed, who described the challenges of addressing cultural specificities of GBV in a context of racialization and xenophobia.

\section{Findings}

\section{Talking About Culture and Violence}

We were in the midst of conducting research on services to address GBV among South Asian communities of the GTA when Aruna Papp, a long-time advocate and outspoken educator/ counsellor, published a memoir chronicling her own experiences as a survivor of what she terms honour-motivated violence (HMV; Papp \& Kay, 2012). Titled Unworthy Creature: A Punjabi Daughter's Memoir of Honour, Shame and Love, the book was co-authored by Barbara Kay, a columnist for the conservative National Post newspaper, and on its release the memoir received support from within the Conservative government. Papp defined HMV as a product of ancient cultural traditions that persist among South Asian immigrants in Canada (see also Papp, 2010). She took issue with what she saw as the framing of HMV by multiculturalists as "just an extreme form" (pp. iii-iv) of the domestic violence that was experienced by all women and girls regardless of culture. In her eyes, this framing was fuelled by white Canadians' fears of appearing racist, and ultimately kept victims of HMV from receiving the help they needed to overcome cultural "brainwashing” (pp. 210-211). In May 2012, the Minister for Status of Women at the time, Rona Ambrose, hosted an official reception to launch the book, stating that "Aruna Papp demonstrates that the barbaric practices associated with 'honour' motivated violence have no place in Canada, and that we must reject them using clear language of freedom and equality" (Status of Women Canada, 2012). The book's front cover, which featured the veiled face of an Indian bride looking up and away from the reader's gaze, was captioned by a written testimonial from Minister Ambrose that read: "A woman's courageous witness to the terrors of the 'culture of honour' " (Papp \& Kay, 2012). In 2015, the same government passed the Zero Tolerance for Barbaric Cultural Practices Act; Aruna Papp claimed to have influenced the title (Abji et al., 2019).

Given the public attention to the book's release, it was not surprising that Papp's name came up frequently during our interviews with other service providers - Papp's peers - who likewise were actively engaged in the GBV sector. What struck us about these conversations, however, were the clear divergences between the Canadian government's public celebration of Papp's "breaking the silence" about HBV, and the strong concerns and opposing perspectives expressed

by the 15 participants in our study, who, like Papp, were "insiders" within South Asian 
communities of the GTA. Almost all of our interviewees disagreed with Papp's position: they rejected what they saw as stigmatizing and overly simplistic conceptions of "South Asian culture" as barbaric and something that South Asian communities suffered from. In doing so, they drew our attention to the ways in which such problematic uses of culture and honour can act as a barrier to social service provision by fuelling systemic racism against South Asian and immigrant communities, as well as by limiting the capacity of GBV agencies to effectively address the needs of South Asian women experiencing violence (Barnoff, 2001; Shirwadkar, 2004).

At the same time that they rejected such politicized uses of culture, our interviewees also struggled with how to talk publicly about the patterns of violence they witnessed in their work, without resorting to - or having their words coopted by — dominant discourses. Indeed, for many of our respondents, this entailed avoiding questions of culture altogether, whether by insisting that "violence is violence is violence" regardless of culture, or in some cases by using the term "community" instead to try and capture what we as sociologists would label "cultural" specificities of violence (Abji et al., 2019; Korteweg, 2014).

Our interviewees also showed the importance of paying attention to structural forces. For instance, in our conversations with service providers, we did not start by asking about "honour" killing or $\mathrm{HBV}$, thus providing respondents with the opportunity to provide insights beyond the responses elicited by framings of HBV such as those presented in books like Papp's (Papp \& Kay, 2012). Rather, we began our interviews by inviting participants to discuss their own definitions of violence against women. We quickly learned that a significant number of service providers understood such violence as a complex phenomenon — as what we came to call "multiscalar" in a way that ultimately highlighted the interplay of culture with other social forces. Our understanding of GBV as multiscalar was borne out by the attention interviewees gave to the complex intersection of place and space (local, national, transnational) with the multivalent expressions of power (discourse, legality, materiality) that shape life (Laine, 2016; Morceau et al., 2020). Participants brought up various elements of this multiscalar construction of violence. One participant, for example, insisted that we need to expand the very definition of GBV to include structural forms of violence, explaining:

I look at poverty as violence, I look at immigration as violence ... I look at racism as violence and that healing from that is just as important, and how you do that healing too. (Zaina)

Similarly, another advocate saw violence as something that happens "over the lifetime" and that is structured by social conditions and a multiplicity of power relations:

Having worked with women who are coming from immigrant communities and experiencing poverty or homelessness, you start to see that race, class, immigration status, sexual orientation - all of those play a role. (Diya) 
International Journal of Child, Youth and Family Studies (2021) 12(1): 73-92

Reflecting a trend in understandings of GBV as intersectional (Bruckert \& Law, 2018; Crenshaw, 1991; Lépinard, 2014), these responses from interviewees illustrate what we call multiscalar violence - violence produced at multiple and intersecting levels - whether as state violence at the local, national, or international levels; as economic violence; or as societal violence. Interviewees spoke of women having to deal with the state's stringent immigration regulations, and referred to increasingly limited social service provisions as a form of state violence; they reported seeing the economic violence many women experience in the form of poverty and exploitation; and they observed that society-wide violence may be produced through both institutional and everyday acts of discrimination. They viewed these forms of violence as intersecting with and shaping the violence individuals experience at the hands of family members. As we will show, the idea that violence does not occur solely at the individual level or within an intimate relationship framed almost all of our conversations (see also Abji et al., 2019; Korteweg et al., 2013).

We will further show that as service providers, advocates, and activists, our interviewees struggled to find ways to act on this multiscalar understanding of violence in their dealings with funders, state agencies, colleagues, and clients. We identified two major obstacles encountered by our participants as they sought to address the multiscalar patterns of GBV observed in the field: the problem of culture and the obscuring of multiscalarity.

\section{The Problems of Culture Talk}

Addressing violence: The problem of culture

Service providers reported that GBV, particularly among South Asian communities, was viewed in culturally stigmatizing ways by funders, state agencies, colleagues, and the media. For our respondents, problematic conceptions of South Asian culture as monolithic, static, and premodern entailed their own type of violence.

In this context, we noticed that many of our participants struggled with how to understand culture in their work, especially with regard to the link between power and culture. On the one hand, in the media and at public events a problematic "culture" has often been presented as an affliction of South Asian communities, as evidenced by the positive reception of Papp's book. As we have discussed in greater detail elsewhere (Abji et al., 2019), we noted that the people we interviewed rejected such notions wholesale, and in doing so often rejected as well the idea that culture had any impact on women's encounters with violence. On the other hand, their accounts also demonstrated how culture as meaning-making structured the everyday lives of the women using their services. As we show below, our interviewees struggled with the apparent contradiction between these varying uses of culture in politics, the media, and daily life. To avoid the association between culture and stigmatization or racialization, they would often use the term "community"

to capture what we as researchers would describe as cultural meaning-making practices. In this use of community, the interviewees tried to move away from culture talk and its racializing impact. 
The price of treating culture simplistically is high. Most immediately, the lack of recognition of cultural specificities by mainstream GBV agencies can lead to what one advocate in our study labelled "revictimization" in the form of shelters that are ill-equipped to handle women's needs:

Over the last 10 years I have worked with a lot of South Asian women ... [who] ... have termed their experience with those agencies as being violent, if you like, violent in the sense of being oppressed, or of not being given information that could have helped them in a different way.... So for [them] it was better to have lived with the abuser than to be — in [their] terms — to be abused by these other agencies. (Sayeeda)

Such concerns around revictimization pointed to the critical need for more nuanced approaches to culture in antiviolence work, approaches that take seriously the systemic violence inflicted by categories such as "honour" killing and "honour"-based violence, without altogether rejecting recognition of the cultural specificities of violence. In other words, these concerns pointed to a need to move from monolithic culture talk to paying attention to nuanced processes of meaningmaking.

\section{Addressing violence: The obscuring of multiscalar forces}

In addition to the stigmatizing and racializing effects of culture, our participants also indicated that the simplistic accounts of culture that are characteristic of culture talk obscured the multiscalar nature of the violence that women confront. This included problems associated with funding and the structural organization of services that address GBV within a system organized around narrow yet culturally dominant definitions of both the perpetrators of violence and their victims.

For example, a number of interviewees raised the issue of forced marriage, defined as marriage practices that are enforced without both individuals consenting to the match (SALCO, 2013) ${ }^{3}$. In their case descriptions, our participants challenged dominant cultural assumptions about perpetrators and victims that privilege individualistic approaches to GBV. For example, Bipasha described dominant approaches to service provision thus:

... so it's kind of ... validating the woman's experience to a certain degree, but it doesn't really embed it in a sociopolitical, economic context that is this woman's reality in the end. (Bipasha)

We capture the multivalent contexts that Bipasha and others refer to through our articulation of violence as multiscalar. Conventional understandings of domestic partner violence assume one

\footnotetext{
${ }^{3}$ It should be noted that forced marriage is not synonymous with arranged marriage. In an arranged marriage, although the match is arranged by the families, the individuals getting married have a choice of whether or not to marry. In forced marriages, the individuals to be married are not given the opportunity to refuse. The "force" deployed may include emotional, mental, or physical forms of coercion (SALCO, 2013). The issue of forced marriage received significant attention within the communities of the professionals we spoke with.
} 
perpetrator, usually a man, enacting violence in the context of a one-to-one relationship with the victim, usually a woman. However, we learned from the interviews that there may be multiple perpetrators in forced marriage cases including parents, extended family members living here or in other countries, community members and community leaders, and the state itself through its migration regime and the process of criminalization of immigrant communities. That multiscalar forces constrain the possibilities of addressing such cases was also evident: forced marriage cases are often very complex. Sayeeda explained that they require the kinds of funding that are not available under funding models that are scaled to the number of women served rather than the hours necessary to help any particular woman.

In October 2012, the federal Conservative government adopted regulations to combat what they called "fraudulent marriages", adding constraints upon those who wanted to marry a nonCanadian with whom they had been in a relationship for less than two years and with whom they did not have children. Under these rules, the new immigrant in the couple was to receive conditional, rather than permanent, residence status and would need to remain in a "conjugal relationship" for at least two years before graduating to permanent residency (Bhuyan et al., 2018). Such conditional statuses form the basis for increases in GBV. For example survivors may remain in an abusive relationship in order to retain their right to remain in the country, or perpetrators may use fear of criminalization as a tool of power and control (Abji, 2016; Bhuyan et al., 2018; Bhuyan et al., 2014).

A number of participants recounted how their attempts to address forced marriage had been misused to inform the regressive "fraudulent marriage" legislation. Hansa described how efforts by her and her colleagues to educate mainstream media about forced marriage backfired when information they had provided was used by the state as a pretext for enacting the new restrictions on sponsoring spouses:

The issue of forced marriage came about because media was constantly referring to South Asian marriages as arranged marriages and so there needed to be an understanding that there is a difference between an arranged marriage and a marriage that is for the purposes of coercion, seduction, and deception.... [Now] I am concerned because I know the government has been misusing all of this information.... So instead of saying forced marriage, they come out with the term "fraud marriage" ... which is a very serious concern for us, so we have to be very very careful about how we are going to shape the conversation so that the women, the very women that we are trying to help, are not women impacted by any negative reprisals through the new legislative reforms. (Hansa)

For Hansa, speaking out about patterns of GBV within South Asian communities had become a risky act within a context of multiscalar violence. In this case, acts of violence were invoked not to address the needs of its female victims but to criminalize and restrict immigration of racialized communities. 
Such observations led the people we interviewed to view the patterns of violence among South Asian communities as multiscalar and complex. When South Asian women turn to the authorities for help, they may encounter structural forms of violence such as having a precarious immigration status that limits their access to supports (Abji, 2016, 2018), or they may experience revictimization when accessing a system that misrecognizes their specific needs and ignores the relationships that bind them to family and community. The funding models in effect at the time further undermined those service providers who had a more comprehensive analysis of women's needs and were willing to consider alternative practices. During the period of our research, funders increasingly focused on services that targeted all women or all victims of violence, and cut back on funds for targeted community-based work. Taken as a whole, our findings suggest that effective service delivery requires an understanding of women's needs as complex, and violence as occurring at multiple levels in society: service-delivery models that aim to address just one aspect of experience without regard to context are certain to fall short.

Indeed, in an environment where the accounts of Papp (Papp \& Kay, 2012) and others who shared her perspective informed a homogeneous view of "culture" — what we call culture talk — that produced racializations of entire communities, having conversations within these communities became more difficult: service providers struggled to recognize needs without contributing to stigmatization and racialization of the communities with which they were interacting. In response to Papp's memoir, its subsequent endorsement by a federal minister, and its impact on legislation, a number of the providers we interviewed observed that such accounts are divisive in the communities that confront the types of violence Papp sought to address. As one of the advocates in our study argued, the racializing effect of Papp's account led to calls for a united front in what many perceived as sustained attacks on their community in public and media debates. She felt that this led to a struggle amongst social service providers trying to negotiate these complexities of culture:

If we are going to pander to those sensibilities — then we can't have real conversations - do you know what I am saying? — we can't have real conversations about, about the authentic needs of women. (Bipasha)

A number of participants argued that we should not talk about culture at all but rather insist that, in the words of Hansa, "violence is violence is violence", thus universalizing the experience of violence in an attempt to break through the culturally-based stigmatization and racialization of South Asian communities. However, the price of this strategy was an inability to articulate claims for a reanalysis of violence against women as complex and multiscalar, in which culture is about the everyday meaning-making processes and practices that shape women's experiences. 
International Journal of Child, Youth and Family Studies (2021) 12(1): 73-92

\section{Discussion}

\section{Reconsidering Culture As Meaning-Making: Alternative Approaches}

The struggles reported by participants might be taken to suggest that all notions of culture in conceptualizing violence against women should be rejected. We argue otherwise. While much of the political response to $\mathrm{HBV}$ hinged on particular regressive notions of culture, this does not render the notion of culture useless in addressing HBV. We argue that by understanding culture as processes of meaning-making rather than as a monolithic and deterministic force, we can clarify that culture informs all forms of violence in majority groups as well as minority groups. In short, culture gives meaning to practices, including practices of violence. Furthermore, as a process of meaning-making, culture conditions responses to violence on the part not only of individuals but of institutions at the community and state level, including social service agencies, activist and advocacy organizations, government bureaucracies, legislatures, and legal institutions. Members of both majority and minority groups within immigrant-receiving societies give meaning to gender relations, family configurations, the immigration experience, and interpretation of religious doctrines in ways that inform HBV at both the individual and institutional levels (Berman et al., 2009; Raj \& Silverman, 2002; Sev'er \& Yurdakul, 2001).

As we noted in our introduction, an interpretation of $\mathrm{HBV}$ as the result of backward, violent cultures informed the 2015 passage of the Zero Tolerance for Barbaric Cultural Practices Act. The Liberal government elected in late 2015 changed the name of the Act (Bill S-210), removing the reference to "barbaric cultural practices"; the website of Status of Women Canada changed references to HBV by adding the qualifier "so-called" to indicate its rejection of culture talk. ${ }^{4}$ However, our findings suggest that such strategies avoid the trap of regarding culture as "backward" only at the cost of embracing the idea that "culture does not matter" and placing HBV under the more general GBV umbrella. Our findings indicate that we need to acknowledge culture as meaning-making in order to recognize the influence of multiscalar forces and thus to address the multiplicity of ways in which people experience violence and the consequent lack of a single overarching remedy.

In this regard, we have developed two analytical concepts. We use the term "culture talk" to identify processes in which "culture" is used "in essentializing ways that create structural inequalities" (Abji et al., 2019; see also Mamdani, 2007; Razack, 1994). We distinguish this from the patterned practice of "culture-as-meaning-making to understand experiences of and responses to gendered violence across varied communities and social groupings. Importantly, culture-as-

\footnotetext{
${ }^{4}$ At the time of this publication, the federal government has again changed its use of the term HBV. The Department of Women and Gender Equality (WAGE), formerly Status of Women Canada, no longer lists "so-called" HBV at all as a specific form of GBV. There is one mention of "honour" under the category of family violence, where "different types of family violence [can include] harmful practices [such as]: underage or forced marriage, female genital mutilation/cutting, and violence committed in the name of 'honour'" (see WAGE https://cfcswc.gc.ca/violence/knowledge-connaissance/fv-vf-en.html).
} 
meaning-making centers rather than elides the complex forces that shape experiences of violence" (Abji et al., 2019, p. 798). Our approach to culture allows us to avoid the universalism of culture talk, which essentializes practices by attributing them to an identifiable group with the effect of excluding that group from the larger polity. Culture as meaning-making enables situated knowledge production (Haraway, 1988), where the meaning is about how to interpret the multiscalar facets of all acts of violence.

Through this more nuanced understanding of culture as meaning-making, we can also focus on the need for the more integrated vision of violence as multiscalar that service providers identified. We end by focusing on three specific policies that our interviewees outlined: developing multiscalar models of service provision, recognizing families and communities as complex, and integrating survivor stories.

\section{Policy Implications}

Operationalizing multiscalar models: Most concretely, providers discussed the need for risk assessment tools and safety planning guidelines that take seriously multiple perpetrators at the family and community level while also recognizing that the multiscalar violence, including state violence, that women encounter in their daily lives can deter them from seeking out and receiving support. For example, a number of interviewees discussed the importance of providing service as a key component of safety, regardless of immigration status. Likewise, providers expressed a preference for collaborative service provision over the existing "silo" approach, which privileges individualistic understandings of GBV and incites competition among agencies, preventing meaningful collaborations. In an effort to describe what this more authentic cross-sectoral collaboration might look like with reference to an individual client, Diya asked:

What would it mean if we [working across agencies] were actually all sitting around the table, planning on that person's safety? Not looking at our agency, but talking about what would we do so this client gets what she needs and she is safe and her children are safe and wherever she is in the community, she has support?

\section{Recognizing families and communities as complex sites of individual and collective} trauma as well as spaces of healing and resiliency: One of the ways culture talk functions is to portray immigrant families as inherently oppressive to women, and freedom from violence as contingent on leaving the family. However, interviewees suggested that family and community were regarded as meaningful resources in women's lives. At the same time, because of the multiscalar nature of violence experienced by many women, the idea that the solution lies in leaving one's family or one's community obscured the multiple sites of violence that racialized and immigrant women may encounter. The approach of removing women from an abusive relationship is also problematic in that it is based on the premise that multiscalar forces involving housing, poverty, and immigration law, for example - are not an issue for women. A number of our interviewees suggested the need for models that provide a space for temporary relief from multiscalar violence, something that women were not finding in the mainstream shelter 
system. Such an approach recognizes that women are not necessarily going to leave their families or their communities, as these may provide important supports for coping with other sources of racism and oppression. Zaina, for example, discussed a need to move beyond "this one-on-one counselling piece" to incorporate art or classical dance as forms of collective healing. She went on to explain: "Maybe it's doing a shelter that's not called a shelter but, like, it's called a safehouse where women can use it as a negotiation space - just come and take a moment to breathe and kinda regroup and go back out there." What would make this new proposed shelter model different is that it begins from the premise that shelter is a temporary reprieve, rather than the current model's assumption that shelters provide a way out and that women who return to their prior situations have somehow failed.

Integrating survivor stories: Integrating the voices, experiences, and insights of survivors of violence was also put forward by our interviewees as a concrete strategy for addressing the mismatch between GBV service delivery and South Asian women's needs. However, providers cautioned against tokenistic uses of survivor stories. This consideration suggests the use of an intersectional approach, one that recognizes the multiplicity of voices and experiences rather than privileging individual voices as speaking for the collective. Referencing Papp's (Papp \& Kay, 2012) memoir, one participant described what she saw as "the danger of that single story" or the notion that "there is only one valid story and that's mine because it's my lived experience" (Bipasha). Another participant described a DVD collection she and her colleagues were putting together that offered a multiplicity of narratives from survivors that consciously focused on their strategies of self-care and community care rather than being a "confessional" of the details of their abuse (Isha). Instead of approaching survivors' voices in stigmatizing ways, then, these interviewees sought out approaches that, while recognizing the life histories of survivors as important sources of knowledge and healing, embedded those narratives and perspectives within their larger social and political contexts. This approach to stories suggests the central importance of meaning-making in addressing violence.

What links the above three proposals for improving service provision is our interviewees' underlying commitment toward more fundamental change. One, Bipasha, even framed this as a need for a "little revolution":

[To] build resiliency we need to really look at sustainable models of working together and moving beyond silos. Really having those difficult conversations about what can we do, do we have access to information, you know, what you are doing, what I am doing, and really, I think it requires a little revolution, to be quite honest. Like rethinking the way we do our work and a real amount of solidarity that needs to happen. (Bipasha)

Instead of simply adding special programming for South Asian women to the existing institutional organization of GBV service provision, our interviewees favoured an approach that 
International Journal of Child, Youth and Family Studies (2021) 12(1): 73-92

would encourage challenging the more foundational assumptions of current models, and rethinking GBV more broadly as it affects all communities.

\section{Conclusion}

Accounts like Papp's (Papp \& Kay, 2012), which reduce the complexities of interpersonal violence to a simplistic explanation that reflects the strategies of culture talk, are perhaps appealing to those with legislative reponsibility for improving the lives of women in Canada. Similarly, to discount the understanding of culture as meaning-making — as reflected in the terminology that has been adopted by Canada's present Liberal government — treats populations as homogeneous and obscures certain experiences. Neither strategy allows for a more expansive vision - one recognizing that all forms of violence are culturally informed, in the sense that violence and the responses to it are imbued with meanings rooted in specific positionalities and experiences at multiple scales. Instead, the violence experienced by dominant groups in society becomes the norm to which legal and policy efforts respond.

Western institutional practices, whether legal, educational, or pertaining to the provision of social welfare, are often predicated on notions of "rational" or "objective" assessments of social problems, and the rights and responsibilities attached to membership in society. Yet these ideas of rationality and objectivity are themselves cultural in that they do the work of culture as meaningmaking by providing interpretative frames and guides for action. From this vantage point, the linking of immigrants with "culture" becomes moot: it is not a matter of the West having culture, which can be manipulated rationally, and immigrant "others" being culture (Brown, 2009). Rather, the question is: What are the cultural frameworks that give meaning to a person's actions, and how are these informed by the forces that correspond to the various identifications that a person might claim: immigrant, judge, teacher, lawyer, woman, man, gay, straight, white, Black, Brown, or Indigenous? From this perspective of culture as fine-grained processes of meaning-making that are informed by their social and political context, patterns of violence can be understood as developing at the intersections of gender, race, ethnicity, religion, and an immigrant-receiving society's cultural, social, political, and legal practices — in short, as multiscalar, and given meaning in specific ways. 
International Journal of Child, Youth and Family Studies (2021) 12(1): 73-92

\section{References}

Abji, S. (2016). "Because deportation is violence against women": On the politics of state responsibility and women's human rights. Social Politics: International Studies in Gender, State \& Society, 23(4), 483-507. doi:10.1093/sp/jxw004

Abji, S. (2018). Postnational acts of citizenship: How an anti-border politics is shaping feminist spaces of service provision in Toronto, Canada. International Feminist Journal of Politics, 20(4), 501-523. doi:10.1080/14616742.2018.1480901

Abji, S., Korteweg, A. C., \& Williams, L. H. (2019). Culture talk and the politics of the new right: Navigating gendered racism in attempts to address violence against women in immigrant communities. Signs: Journal of Women in Culture and Society, 44(3), 797-822. $\underline{\text { doi:10.1086/701161 }}$

Abu-Lughod, L. (2011). Seductions of the "honor crime". Differences: A Journal of Feminist Cultural Studies, 22(1), 17-63. doi:10.1215/10407391-1218238

Barnoff, L. (2001). Moving beyond words: Integrating anti-oppression practice into feminist social service organizations. Canadian Social Work Review, 18(1), 67-85.

Berman, H., Alvernaz Mulcahy, G., Forchuk, C., Edmunds, K. A., Haldenby, A. \& Lopez, R. (2009). Uprooted and displaced: A critical narrative study of homeless, Aboriginal, and newcomer girls in Canada. Issues in Mental Health Nursing, 30(7), 418-430. doi:10.1080/01612840802624475

Bhuyan, R., Osborne, B., Zahraei, S., \& Tarshis, S. (2014). Unprotected, unrecognized: Immigration policy and violence against women [Report]. Migrant Mothers Project, University of Toronto. https://www.migrantmothersproject.com/report-2/

Bhuyan, R., Korteweg, A. C., \& Baqi, K. (2018). Regulating spousal migration through Canada's multiple border strategy: The gendered and racialized effects of structurally embedded borders. Law \& Policy, 40(4), 346-370. doi:10.1111/lapo.12111

Bourdieu, P. (1977). Outline of a theory of practice (Vol. 16). Cambridge University Press.

Brown, W. (2009). Regulating aversion: Tolerance in the age of identity and empire. Princeton University Press.

Bruckert, C., \& Law, T. (2018). Women and gendered violence in Canada: An intersectional approach. University of Toronto Press.

Crenshaw, K. (1991). Mapping the margins: Intersectionality, identity politics, and violence against women of color. Stanford Law Review, 43(6), 1241-1299. doi:10.2307/1229039 
International Journal of Child, Youth and Family Studies (2021) 12(1): 73-92

Fischer, C., \& Dahinden, J. (2017). Gender representations in politics of belonging: An analysis of Swiss immigration regulation from the 19th century until today. Ethnicities, 17(4), 445-468. doi:10.1177/1468796816676844

Geertz, C. (1973). The interpretation of cultures. Basic Books.

Guimont Marceau, S., Romero, D. F., Estrada, V. J., \& Rice, R. (2020) Approaching violence against Indigenous women in the Americas from relational, intersectional and multiscalar perspectives, Canadian Journal of Latin American and Caribbean Studies / Revue canadienne des études latino-américaines et caraïbes, 45(1), 5-25. doi:10.1080/08263663.2020.1690769

Hall, S. (1997). The spectacle of the "other". In S. Hall (Ed.), Representation: cultural representations and signifying practices (pp. 230-290). Sage \& Open University.

Haraway, D. (1988). Situated knowledges: The science question in feminism and the privilege of partial perspective. Feminist Studies, 14(3), 575-599. doi:10.2307/3178066

Jiwani, Y. (2005). Walking a tightrope: The many faces of violence in the lives of racialized immigrant girls and young women. Violence Against Women, 11(7), 846-875. doi: $10.1177 / 1077801205276273$

Korteweg, A. C. (2014). 'Honour killing' in the immigration context: Multiculturalism and the racialization of violence against women. Politikon: South African Journal of Political Studies, 41(2), 183-208. doi:10.1080/02589346.2013.866186

Korteweg, A. C., Abji, S., Barnoff, L., \& Mattoo, D. (2013). Citizenship, culture, and violence against women: Social service provision in the South Asian communities of the GTA [CERIS research report]. http://www.torontolip.ca/Portals/0/Resources/General/Citizenship, Culture, and Violence Against Women CERIS report.pdf

Korteweg, A. C., \& Yurdakul, G. (2009). Islam, gender, and immigrant integration: Boundary drawing in discourses on honour killing in the Netherlands and Germany. Ethnic and Racial Studies, 32(2), 218-238. doi:10.1080/01419870802065218

Korteweg, A. C., \& Yurdakul, G. (2010). Religion, culture and the politicization of honourrelated violence: A critical analysis of media and policy debates in Western Europe and North America [PP-GD-12]. United Nations Research Institute for Social Development.

Laine, J. P. (2016). The multiscalar production of borders. Geopolitics, 21(3), 465-482, doi:10.1080/14650045.2016.1195132

Lépinard, É. (2014). Doing intersectionality: Repertoires of feminist practices in France and Canada. Gender \& Society, 28(6), 877-903. doi:10.1177/0891243214542430 
International Journal of Child, Youth and Family Studies (2021) 12(1): 73-92

Mamdani, M. (2007, March 8). The politics of culture talk in the contemporary war on terror. Hobhouse Memorial Public Lecture, London School of Economics.

Papp, A. (2010). Culturally-driven violence against women: A growing problem in Canada's immigrant communities. Frontier Centre for Public Policy: FCPP Policy Series No. 92. https://www.fcpp.org/files/1/Culturally-Driven $\% 20$ Violence $\% 20$ Against $\% 20$ Women.pdf

Papp, A., \& Kay, B. (2012). Unworthy creature: A Punjabi daughter's memoir of honour, shame and love. Freedom Press Canada.

Raj, A., \& Silverman, J. (2002). Violence against immigrant women: The roles of culture, context and legal immigrant status on intimate partner violence. Violence Against Women, 8, 367-398. doi:10.1177/10778010222183107

Razack, S. (1994). What is to be gained by looking White people in the eye? Culture, race, and gender in cases of sexual violence. Signs, 19(4), 894-923. doi:10.1086/494944

Razack, S. (2003). A violent culture or culturalized violence? Feminist narratives of sexual violence against South Asian women. Studies in Practical Philosophy, 3(1), 80-104. doi:10.5840/STUDPRACPHIL2003317

Razack, S. (2008). Casting out: The eviction of Muslims from Western law and politics. University of Toronto Press.

Sev'er, A, \& Yurdakul, G. (2001). Culture of honor, culture of change: A feminist analysis of honor killings in rural Turkey. Violence Against Women, 7(9), 964-998. doi:10.1177/10778010122182866

Shirwadkar, S. (2004). Canadian domestic violence policy and Indian immigrant women. Violence Against Women, 10(8), 860-879. doi:10.1177/1077801204266310

Siddiqui, H. (2000). Domestic violence and Black/minority women: Enough is enough! Criminal Justice Matters, 42(1), 14-15. doi:10.1080/09627250008552878

South Asian Legal Clinic of Ontario (SALCO). (2013). https://salc.on.ca/forced-marriage/

Swidler, A. (1986). Culture in action: Symbols and strategies. American Sociological Review, 51(2), 273-286. doi:10.2307/2095521

Status of Women Canada. (2012, May 15). Breaking the silence on acts of violence committed in the name of honour [News release]. Government of Canada. https:/www.canada.ca/en/news/archive/2012/05/breaking-silence-acts-violence-committedname-honour.html 
International Journal of Child, Youth and Family Studies (2021) 12(1): 73-92

Van Dijk, T. A. (1993). Principles of critical discourse analysis. Discourse \& Society, 4(2), 249283. doi:10.1177/0957926593004002006

Volpp, L. (2000). Blaming culture for bad behavior. Yale Journal of Law and the Humanities, 12, 89-117.

Williams, R. (1977). Marxism and literature. Oxford University Press.

Wodak, R., \& Meyer, M. (Eds.). (2015). Methods of critical discourse studies. Sage.

Zero Tolerance for Barbaric Cultural Practices Act: An Act to Amend the Immigration and Refugee Protection Act, the Civil Marriage Act and the Criminal Code and to Make Consequential Amendments to Other Acts 2015 Bill S-7 (Canada). https://www.parl.ca/DocumentViewer/en/41-2/bill/S-7/royal-assent/page-24

Zine, J. (2009). Unsettling the nation: Gender, race, and Muslim cultural politics in Canada. Studies in Ethnicity and Nationalism, 9(1), 146-163. 